Roger Williams University

DOCS@RWU

2010

\title{
Traumatic events, perceived stress, and health in women with fibromyalgia and healthy controls
}

Bruce W. Smith

University of New Mexico,

Erin M. Tooley

Roger Williams University, etooley@rwu.edu

Follow this and additional works at: https://docs.rwu.edu/fcas_fp

Part of the Psychology Commons, and the Public Health Commons

\section{Recommended Citation}

Smith, B. W., Zsuzsanna Z. Papp, , Erin,Tooley, Erica Q. Montague, Amanda E. Robinson and Cynthia J. Cosper. 2010. "Traumatic events, perceived stress, and health in women with fibromyalgia and healthy controls." Stress and Health 26 (1): 83-93.

This Article is brought to you for free and open access by the Arts and Sciences at DOCS@RWU. It has been accepted for inclusion in Arts \& Sciences Faculty Publications by an authorized administrator of DOCS@RWU. For more information, please contact mwu@rwu.edu. 
RESEARCH ARTICLE

\title{
Traumatic Events, Perceived Stress and Health in Women with Fibromyalgia and Healthy Controls
}

\author{
Bruce W. Smith ${ }^{1 *^{\dagger}}$, Zsuzsanna Z. Papp ${ }^{2}$, Erin M. Tooley ${ }^{1}$, Erica Q. Montague ${ }^{1}$, \\ Amanda E. Robinson ${ }^{3}$ \& Cynthia J. Cosper ${ }^{1}$ \\ 'University of New Mexico, Albuquerque, NM, USA \\ ${ }^{2}$ Eötvös Loránd University, Budapest, Hungary \\ ${ }^{3}$ University of Windsor, Windsor, Ontario, Canada
}

\section{Summary}

This study examined the relationship between trauma, stress and health in 41 women with fibromyalgia (FM) and 44 women who were healthy controls (HC). The participants were assessed for traumatic events, perceived stress and mental and physical health. Perceived stress was related to worse mental and physical health in both groups. Traumatic events were related to worse mental and physical health in the FM group but were unrelated to health in the HC group. Perceived stress partially mediated the effect of traumatic events on mental and physical health in the FM group. Finally, adult abuse partially mediated the effects of child abuse on adult stress and health. Trauma may have lasting effects on stress and health in women with FM. Copyright @ 2009 John Wiley \& Sons, Ltd.

Received 15 March 2009; Accepted 6 June 2009

Keywords

fibromyalgia; stress, trauma; health; women

*Correspondence

Bruce Smith, MSC03 2220, Department of Psychology, Unviersity of New Mexico, Albuquerque, NM 87131-1161, USA

†Email: bwsmith@unm.edu

Published online 6 July 2009 in Wiley InterScience (www.interscience.wiley.com) DOI: 10.1002/smi.1269

\section{Introduction}

Fibromyalgia (FM) is a chronic pain condition characterized by widespread muscle pain and also associated with fatigue, sleep and cognitive difficulties, and anxiety and depressed mood. The levels of pain, distress and disability have often been found to be greater than in other chronic pain conditions (Davis, Zautra, \& Reich, 2001). The prevalence of FM is estimated to be $2-4$ per cent and is diagnosed 6-7 times more often in women than in men (Jacobsen \& Bredkjaer, 1992; Wolfe, Ross, Anderson, Russell, \& Herbert, 1995). The diagnosis of FM is based on decreased pressure pain thresholds at a minimum of 11 of 18 specific 'tender points' as defined by American College of Rheumatology criteria (Wolfe et al., 1990). FM has been challenging to treat because there is little understanding of its underlying pathophysiology. The search for pathophysiological mechanisms has included the central nervous system (Gracely, Petzke, Wolf, \& Clauw, 2002), the inflammatory response system (Maes et al., 1999) and the hypothalamic-pituitary-adrenal axis (Okifuji \& Turk, 2002).

Although the relative contributions of these systems to the development of FM have yet to be fully determined, each system is involved in stress response and it has become increasingly evident that stress may play an important role in FM (Van Houdenhove \& Egle, 2004). There are at least three important questions that need to be addressed with regard to the role of stress in FM. Firstly, is FM related to increased exposure to 
stress? There is increasing evidence that the ongoing perception of stress may be related to health in women with FM (Murray, Murray, \& Daniels, 2006; Van Houdenhove et al., 2002; Zautra, Hamilton, \& Burke, 1999). In addition, women with FM may have experienced more traumatic events than healthy women or women with other rheumatological disorders (Van Houdenhove et al., 2001; Walker et al., 1997)

These higher levels of traumatic events and perceptions of stress are important because they have consistently been linked to worse health and lower well-being. Traumatic events such as motor vehicle accidents, sexual assault and natural disasters have been linked to increased anxiety, depression and post-traumatic stress disorder (Breslau et al., 1998; Grant, Beck, Marques, Palyo, \& Clapp, 2008; Smith \& Freedy, 2000). In addition, traumatic events have been associated with higher levels of physical symptoms and physical health problems (Baker, Norris, Jones, \& Murphy, 2009; Kubzansky, Koenen, Jones, \& Eaton, 2009; Smith et al., 2009). Finally, perceived stress has frequently been related to worse mental and physical health (Smith \& Zautra, 2002; Young et al., 2004).

Secondly, is FM associated with increased reactivity to stress? Bolger and Zuckerman (1995) identify both exposure to stressful events and reactivity to stressful events as two separate pathways by which stress may affect health. For people with FM, increased reactivity to stressful events may be as important as being exposed to more stressful events. While FM has been characterized as a 'stress-related disorder', Raphael (2006) has argued that FM may be better described as involving increased 'stress vulnerability'. She contends that the development of FM may be influenced more by an increased reactivity to stressful events than by experiencing a greater number of stressful events.

The view that FM is a stress vulnerability disorder is consistent with research showing that people with FM may have stable characteristics related to higher stress reactivity that may precede the development of FM symptoms. Firstly, women with FM have scored higher on measures of neuroticism than healthy women (Netter \& Hennig, 1998) and women with osteoarthritis (Zautra, Johnson, \& Davis, 2005). Neuroticism is a stable personality characteristic that has been related to sensitivity or reactivity to stress (Bolger \& Zuckerman, 1995). Secondly, there is reason to suspect that FM may also be associated with a greater central nervous system sensitization to pain (Desmeules et al., 2004; Gracely et al., 2002), which may be a stable neurological characteristic that precedes the onset of FM symptoms.

Thirdly, are the stress and health of people with FM related to the experience of traumatic events? There is evidence that traumatic events may lead to both increase in stress and worse health across the lifespan (McEwen, 1998; Sapolsky, 1999). Individuals with FM often report higher current levels of stress than healthy controls and those with other chronic pain conditions (Davis et al., 2001; Zautra et al., 2005). Traumatic events may be a predisposing factor for both higher stress and worse health in FM (Walker \& Katon, 1996; Weissbecker, Floyd, Dedert, Salmon, \& Sephton, 2006). If so, it may be important not only to consider current stress as a predictor of health but also as a mediator of the effects of traumatic events on health in FM. The impact of trauma on the health may be both direct and indirect through increasing current stress.

The most damaging forms of early traumatic events may be the physical, sexual or emotional abuse that sometimes occurs in childhood (Gibb, Chelminski, \& Zimmerman, 2007; Walker et al., 1997). The effects of these kinds of child abuse may persist into adulthood and have lasting negative effects on mental and physical health (Gunstead et al., 2006; Vranceanu, Hobfoll, \& Johnson, 2007). In addition, child abuse has been linked to increased stress in adulthood in the form of domestic violence and relationship abuse (Campbell, Greeson, Bybee, \& Raja, 2008; Widom, Czaja, \& Dutton, 2008). Indeed, the effects of child abuse on adult health may be at least partially mediated by their effects on adult relationships (Vranceanu et al., 2007; Whiffen \& Macintosh, 2005).

Women with FM have reported higher levels of child abuse than women with other chronic pain conditions (Van Houdenhove et al., 2001; Walker et al., 1997). There is evidence suggesting that early trauma may be a predisposing factor for the development of pain and stress-related disorders (Glaser, Van Os, Portegijs, \& Myin-Germeys, 2006; Walsh, Jamieson, Macmillan, \& Boyle, 2007). Thus, it may be necessary to consider traumatic events over a lifetime including their type, intensity and duration. For example, child abuse may be a type of abuse that potentially has a greater cumulative impact than adult abuse (Nemeroff, 2004; Weber \& Reynolds, 2004). If so, then interventions focused on the prevention of abuse or support for abused children may help reduce the risk of ongoing distress and possibly the development of FM symptoms in adulthood 
(Reynolds, Mathieson, \& Topitzes, 2009; Widom et al., 2008).

\section{Current study}

The purpose of this study was to address these three questions about the role of stress in FM by examining women with FM and healthy control women (HC). We assessed both the number of lifetime traumatic events and the current level of perceived stress. The measure of traumatic events was divided into child abuse, adult abuse and other traumatic events. We separated relationship abuse from other traumatic events because interpersonal stress may play a unique role in FM (Davis et al., 2001; Zautra et al., 1999). We distinguished between child abuse and adult abuse to examine their differential role in predicting current health and to determine whether child abuse predicted adult abuse (Hyman, Paliwal, \& Sinha, 2007). Finally, we assessed health using the SF-36 Health Survey (Ware, Snow, Kosinski, \& Gandek, 1993) because it includes mental and physical health summary scores and a full range of subscales.

Our hypotheses are based on the three questions about FM and stress. Firstly, is FM related to increased exposure to stressful events? We predicted that women with FM relative to the healthy women would report (1) more traumatic events and (2) greater perceived stress. Secondly, is FM related to increased reactivity to stress? We predicted that women with FM relative to healthy women would have (3) stronger relationships between perceived stress and health and (4) stronger relationships between traumatic events and health. Thirdly, are the stress and health of people with FM related to the experience of traumatic events? For the FM group we predicted that (5) perceived stress would mediate the effects of traumatic events on health and (6) adult abuse would mediate the effects of child abuse on perceived stress and health.

\section{Method}

\section{Participants}

The sample consisted of 85 women who had FM $(n=41)$ or women who were HC $(n=44)$. The study was conducted in compliance with the Institutional Review Board of the University of New Mexico, and informed consent was obtained by trained research assistants. The participants were recruited through newspaper ads and rheumatology clinics in the local community. Only women between the ages of 30 and 60 were recruited for the study. All participants were paid US\$20 for completing the study.

The women in the FM group had their FM diagnosis confirmed by a physician. The diagnosis was confirmed with the completion of a diagnosis confirmation form by the physician or other authorized person working in the physician's office. The majority of confirmations were by a rheumatologist who provided referrals for the study. In addition, the participants had an average pain rating for the past month of at least 20 on a $0-100$ scale $(0=$ no pain and $100=$ pain as bad at it can be $)$, had pain in all four quadrants (e.g. both arms and legs) and had no other conditions that caused greater pain. The women in the HC group had average pain ratings of less than 20 on a $0-100$ scale, had no pain-related diagnoses (e.g. FM, osteoarthritis, rheumatoid arthritis) and reported that they were not currently depressed nor taking antidepressant medications.

There were no differences between the FM and HC groups in age, per cent married or ethnicity. The participants were between the ages of 30 and 60 (mean = 48.44 , standard deviation $=6.91$ ). The majority were married (48 per cent) while fewer were divorced ( 32 per cent), never married (18 per cent) or widowed ( 2 per cent). The majority were Caucasian (64 per cent) while fewer were Hispanic (26 per cent), Native American (1 per cent), Asian-American (1 per cent) or mixed or other ( 8 per cent). The FM group had a lower mean income range than the HC group (US\$21,000-\$24,999 vs. US\$40,000-\$49,999, $t(83)=2.833, p<0.006)$. The FM group also had a lower per cent of college graduates (39 per cent vs. 64 per cent, $\chi^{2}(1)=5.149, p=0.023$ ) and a lower per cent employed than the HC group (51 per cent vs. 86 per cent, $\chi^{2}(1)=12.346, p=0.000$ ).

\section{Measures}

The participants came to a private room in the research lab of the first author. They filled out questionnaires that included the following measures of mental and physical health, perceived stress, and traumatic events.

\section{Mental and physical health}

The assessment of mental and physical health involved using the 36 items from the SF-36 Health Survey (Ware et al., 1993). The SF-36 contains eight subscales. There are four mental health subscales: (1) emotional well-being; (2) role-emotional (role 
limitations due to emotional problems and social functioning); (3) vitality; and (4) social functioning. There are four physical health subscales: (1) physical functioning; (2) role-physical (role limitations due to physical problems); (3) bodily pain (with lower pain given higher scores); (4) and general health. The four mental health and the four physical health subscales were averaged to form overall mental health and overall physical health scores. Each of the subscales and summary scores provides a score between 0 and 100 with higher scores indicating better health. Cronbach's alpha for the two summary scores and the eight subscales ranged from 0.888 to 0.952 .

\section{Perceived stress}

This was assessed using the perceived stress scale (Cohen, Kamarck, \& Mermelstein, 1983). This measure includes ten items (e.g. 'How often have you felt difficulties were piling up so high that you could not overcome them?' and 'How often have you felt that you were unable to control the important things in your life?'). The items were assessed in relation to the past month and were scored on a four-point scale from $1=$ never to 4 = fairly often. Cronbach's alpha was 0.917 .

\section{Traumatic events}

We asked whether participants had ever experienced any of a list of 13 traumatic experiences and events. The 13 items included three items to assess child abuse, three items to assess adult abuse and seven items to assess other trauma likely to be experienced by adult women. The child and adult abuse items assessed physical, sexual and emotional abuse. The additional events were selected from standard lists of traumatic events and included being the victim of a crime (other than unwanted sexual contact which was considered to be part of sexual abuse), having witnessed death, having experienced an injury or illness that might have caused death, having experienced a natural disaster, and having experienced a fire or an explosion (Norris \& Hamblen, 2004).

In addition, we asked whether participants had ever experienced a car, bus, truck, boat, train or plane accident because accidents frequently precede the report of symptoms in people with FM (Al-Allaf et al., 2002). Our goal was to create internally consistent summary scores for total traumatic events, child abuse, adult abuse and other (non-abuse related) traumatic events.
The Kuder-Richardson Formula 20 reliability scores for these dichotomous items were 0.767, 0.731, 0.772 and 0.620 for overall traumatic events, child abuse, adult abuse and other trauma events, respectively.

\section{Statistical analyses}

Chi-square tests were used to examine differences between the FM and HC groups on the report of individual traumatic events. Independent samples $t$-tests were used to test the first and second hypotheses regarding group differences on the stress measures. Correlation analyses assessed the relationship between the perceived stress, traumatic events and health measures. Fisher's $z$ transformations were performed to test the third and fourth hypotheses in comparing the correlations between the FM and HC (Kleinbaum, Kupper, \& Muller, 1988). The fifth hypothesis was tested using multiple regression and the Baron and Kenny criteria (Baron \& Kenny, 1986) for assessing mediation; and the sixth hypothesis was tested using structural equation modelling. The statistical software package AMOS version 4.0 was used for the structural equation modelling and SPSS version 16.0 was used for all other analyses. An alpha of $p<0.05$ was the criterion for significance in all statistical tests.

\section{Results}

\section{How did the FM and HC groups compare on the occurrence of specific traumatic events?}

Table I shows the group percentages and comparisons for each of the traumatic events. More than half of the women in the FM group reported an accident or emotional abuse as a child. Between one-third and one-half in the FM group reported physical abuse as a child, sexual abuse as a child, physical abuse as an adult, emotional abuse as an adult, being the victim of a crime (other than sexual abuse) or having witnessed death. Less than one-third in the FM group reported having experienced sexual abuse as an adult, a fire/explosion, an injury or illness that may have caused death, or a natural disaster. The women in the FM group were roughly three times as likely to report physical, sexual, or emotional abuse as a child, sexual or physical abuse as an adult as women in the HC groups. All of these differences were significant except for sexual abuse as an adult. 
Table I. FM and HC group percentages and comparisons for specific traumatic events

\begin{tabular}{|c|c|c|c|c|}
\hline Type of traumatic event & FM (per cent) & $\mathrm{HC}$ (per cent) & $\chi^{2}$ & $p$ \\
\hline \multicolumn{5}{|l|}{ Child abuse } \\
\hline Physical abuse & 34.15 & 11.36 & 6.347 & 0.012 \\
\hline Sexual abuse & 34.15 & 11.36 & 6.347 & 0.012 \\
\hline Emotional abuse & 58.54 & 18.18 & 14.724 & 0.000 \\
\hline \multicolumn{5}{|l|}{ Adult abuse } \\
\hline Physical abuse & 34.15 & 13.64 & 4.692 & 0.026 \\
\hline Sexual abuse & 17.07 & 6.82 & 2.150 & 0.143 \\
\hline Emotional abuse & 43.90 & 31.82 & 1.320 & 0.251 \\
\hline \multicolumn{5}{|l|}{ Other Trauma } \\
\hline Victim of a crime ${ }^{\star}$ & 34.15 & 31.82 & 0.052 & 0.819 \\
\hline Witnessed death & 41.46 & 45.45 & -0.138 & 0.711 \\
\hline Experienced a fire/explosion & 9.76 & 15.91 & -0.713 & 0.398 \\
\hline Accident (e.g. car, bus, boat, train, plane) & 65.85 & 54.55 & 1.131 & 0.288 \\
\hline Injury or illness that might have caused death & 26.83 & 25.00 & 0.037 & 0.847 \\
\hline Natural disaster (e.g. flood, hurricane, tornado, earthquake) & 21.95 & 11.36 & 1.729 & 0.189 \\
\hline
\end{tabular}

${ }^{\star}$ Other than unwanted sexual contact which is included as part of sexual abuse.

FM: fibromyalgia; HC: healthy control.

Table II. Descriptive statistics and FM and HC group comparisons for traumatic events, perceived stress and health measures

\begin{tabular}{|c|c|c|c|c|c|c|c|}
\hline \multirow[t]{2}{*}{ Measure } & \multicolumn{2}{|c|}{ FM } & \multicolumn{2}{|c|}{$\mathrm{HC}$} & \multirow[t]{2}{*}{$t$} & \multirow[t]{2}{*}{$p$} & \multirow[t]{2}{*}{$d$} \\
\hline & Mean & SD & Mean & $\mathrm{SD}$ & & & \\
\hline \multicolumn{8}{|l|}{ Traumatic events } \\
\hline Overall events & 4.22 & 2.81 & 2.77 & 2.30 & 2.606 & 0.011 & 0.564 \\
\hline Child abuse & 1.27 & 1.10 & 0.41 & 0.87 & 3.982 & 0.000 & 0.867 \\
\hline Adult abuse & 0.95 & 1.12 & 0.52 & 0.88 & 1.959 & 0.054 & 0.427 \\
\hline Other events & 2.00 & 1.47 & 1.84 & 1.57 & -0.482 & 0.550 & 0.105 \\
\hline Perceived stress & 2.09 & 0.70 & 1.01 & 0.54 & 7.979 & 0.000 & 1.728 \\
\hline \multicolumn{8}{|l|}{ Mental health } \\
\hline Overall & 39.58 & 19.68 & 84.97 & 9.47 & -13.396 & 0.000 & 2.939 \\
\hline Emotional well-being & 57.66 & 21.76 & 82.98 & 10.39 & -6.765 & 0.000 & 1.485 \\
\hline Role-emotional & 32.55 & 39.78 & 93.04 & 18.41 & -8.890 & 0.000 & 1.952 \\
\hline Vitality & 27.56 & 17.61 & 68.83 & 17.32 & -10.890 & 0.000 & 2.363 \\
\hline Social functioning & 40.55 & 23.68 & 95.05 & 9.00 & -13.836 & 0.000 & 3.043 \\
\hline \multicolumn{8}{|l|}{ Physical health } \\
\hline Overall & 32.14 & 19.58 & 89.43 & 8.92 & -17.173 & 0.000 & 3.766 \\
\hline Physical functioning & 41.54 & 26.54 & 92.17 & 9.10 & -11.597 & 0.000 & 2.552 \\
\hline Role—physical & 16.90 & 29.26 & 95.80 & 15.74 & -15.326 & 0.000 & 3.358 \\
\hline Bodily pain & 33.66 & 15.96 & 84.80 & 12.69 & -16.517 & 0.000 & 3.547 \\
\hline General health & 36.46 & 21.63 & 84.98 & 12.80 & -12.471 & 0.000 & 2.730 \\
\hline
\end{tabular}

FM: fibromyalgia; HC: healthy control; SD: standard deviation.

\section{Did women with FM have more traumatic events, perceived stress and worse health?}

The first hypothesis was that women with FM would report more traumatic events than the healthy women. Table II shows that this hypothesis was generally supported. The FM group reported more overall traumatic events (4.22 vs. $2.77, t=2.606, p=0.011)$ and more child abuse ( 1.27 vs. $0.41, t=3.982, p=0.000$ ). In addition, there was a trend for more adult abuse in the FM group and no significant difference in the sum of other traumatic events.

The second hypothesis was that women with FM would report more perceived stress than the healthy women. Table II shows that this hypothesis was strongly 
supported. The FM group reported much higher levels of perceived stress than the HC group. In addition, as would be expected, the FM group reported much lower levels of mental and physical health relative to the $\mathrm{HC}$ group. The effect size for the group differences were progressively larger for traumatic events, perceived stress, mental health and physical health (Cohen $d s=$ $0.564,1.728,2.939$ and 3.766, respectively).

\section{Were perceived stress and traumatic events related to mental and physical health?}

Table III displays the correlations between the stress and health measures. Perceived stress was related to worse overall mental and physical health for both the FM and HC groups. For the FM group, perceived stress was related to all of the health subscales except vitality and bodily pain, while perceived stress was only related to physical functioning and general health for the $\mathrm{HC}$ group. The correlations between perceived stress and all health measures were larger in the FM group, although none of the differences were significant. Thus, the third hypothesis that the relationship between perceived stress and health would be larger in the FM group was not supported.

Overall traumatic events were related to worse overall mental health and worse overall physical health in the FM group. They were also related to worse health in each of the eight health subscales. In contrast, traumatic events were not related to overall mental or physical health or to any of the health subscales in the $\mathrm{HC}$ group. The differences between the FM and HC groups in the size of the correlations were significant for overall mental and physical health. In addition, the differences between groups were also significant for the social and physical functioning subscales. Thus, the fourth hypothesis that the relationship between traumatic events and health would be larger in the FM group was supported.

\section{What types of traumatic events were related to health?}

We also examined the correlations between specific types of traumatic events and health. These results are also shown in Table III. For the FM group, adult abuse and other traumatic events were each related to worse overall mental and worse overall physical health. Adult abuse and other traumatic events were related to seven and six of the eight subscales, respectively. Child abuse was related to worse physical health with a trend towards worse mental health. Child abuse was also related to the physical and social functioning subscales. In contrast, for the HC group there were no significant correlations between any traumatic event and any health measure. There was a trend for other traumatic events to be related to worse mental and physical health and worse physical functioning.

Finally, in comparing the size of the correlations between the FM and $\mathrm{HC}$ groups, the correlations between adult abuse and overall mental health, overall

Table III. Correlations between traumatic events, perceived stress and the health measures for the FM and HC groups

\begin{tabular}{|c|c|c|c|c|c|c|c|c|c|c|}
\hline & \multicolumn{2}{|c|}{ Perceived stress } & \multicolumn{2}{|c|}{ All traumas } & \multicolumn{2}{|c|}{ Child abuse } & \multicolumn{2}{|c|}{ Adult abuse } & \multicolumn{2}{|c|}{ Other traumas } \\
\hline & FM & $\mathrm{HC}$ & FM & $\mathrm{HC}$ & FM & $\mathrm{HC}$ & FM & $\mathrm{HC}$ & FM & $\mathrm{HC}$ \\
\hline \multicolumn{11}{|l|}{ Mental Health } \\
\hline Overall & $-0.621^{\star *}$ & $-0.309^{*}$ & $-0.567^{\star \star}$ & -0.165 & $-0.265^{\dagger}$ & 0.011 & $-0.531^{\star *}$ & 0.019 & $-0.482^{\star \star}$ & -0.259 \\
\hline Emotional well-being & $-0.678^{* *}$ & -0.243 & $-0.361^{\star}$ & -0.123 & 0.040 & -0.002 & $-0.396^{\star}$ & -0.024 & $-0.420^{*}$ & -0.166 \\
\hline Role-emotional & $-0.481^{\star *}$ & -0.248 & $-0.425^{\star *}$ & -0.216 & -0.168 & -0.135 & $-0.414^{\star *}$ & -0.018 & $-0.372^{\star}$ & -0.232 \\
\hline Vitality & $-0.294^{\dagger}$ & -0.218 & $-0.361^{\star}$ & -0.045 & $-0.276^{\dagger}$ & 0.133 & $-0.305^{\dagger}$ & 0.062 & -0.252 & -0.175 \\
\hline Social functioning & $-0.413^{\star *}$ & -0.094 & $-0.570^{* *}$ & -0.023 & $-0.430^{*}$ & 0.069 & $-0.479^{* *}$ & 0.025 & $-0.405^{\star *}$ & -0.086 \\
\hline \multicolumn{11}{|l|}{ Physical health } \\
\hline Overall & $-0.468^{\star *}$ & $-0.310^{*}$ & $-0.539^{\star *}$ & -0.173 & $-0.350^{*}$ & 0.132 & $-0.496^{\star *}$ & -0.082 & $-0.392^{\star *}$ & $-0.282^{\dagger}$ \\
\hline Physical functioning & $-0.396^{\star}$ & $-0.355^{\star}$ & $-0.485^{\star *}$ & -0.164 & $-0.447^{\star *}$ & 0.037 & $-0.369^{\star *}$ & 0.133 & $-0.394^{\star}$ & $-0.279^{\dagger}$ \\
\hline Role_-physical & $-0.357^{\star}$ & -0.119 & $-0.426^{\star *}$ & -0.037 & -0.237 & 0.104 & $-0.409^{* *}$ & -0.064 & $-0.313^{*}$ & -0.149 \\
\hline Bodily pain & $-0.268^{\dagger}$ & -0.034 & $-0.417^{\star *}$ & -0.142 & $-0.283^{\dagger}$ & 0.009 & $-0.417^{\star \star}$ & -0.171 & $-0.327^{\star}$ & -0.230 \\
\hline General health & $-0.528^{\star *}$ & $-0.433^{* *}$ & $-0.473^{\star *}$ & -0.120 & -0.191 & 0.205 & $-0.483^{\star *}$ & -0.073 & $-0.270^{\dagger}$ & -0.085 \\
\hline
\end{tabular}

${ }^{\dagger} p<0.10 ;{ }^{*} p<0.05 ;{ }^{* *} p<0.01$.

FM: fibromyalgia; HC: healthy control. 
physical health, social functioning, physical functioning, and general health were significantly larger in the FM group. In addition, the correlations between child abuse and both social functioning and physical functioning were also significantly larger in the FM group. Finally, although all of the correlations between other traumatic events and the health measures were larger in the FM group, none of the differences were significant.

\section{Did perceived stress mediate the effects of traumatic events on health in the FM group?}

Our fifth hypothesis was that perceived stress would mediate the effects of traumatic events on mental and physical health in the FM group. The criteria for mediation were that (1) the independent variable (traumatic events) should be related to the mediator (perceived stress); (2) the independent variable should be related to the dependent variable (mental or physical health); and (3) the mediator should still be related to the dependent variable when controlling for the mediator (Baron \& Kenny, 1986). The first criterion was met in that traumatic events were related to perceived stress $(r=0.404, p<0.01)$. The second criterion was met in that traumatic events were related to mental health $(r=-0.567, p<0.01)$ and to physical health $(r=-0.539$, $p<0.01)$.

Multiple regression was used to test third criterion. Perceived stress was still related to mental health when controlling for traumatic events $(\beta=-0.468, p<0.001)$. Also, traumatic events $(\beta=-0.377, p<0.01)$ were still related to mental health, indicating that the effects of traumatic events were both direct and indirect through perceived stress. Similarly, perceived stress was still related to physical health when controlling for traumatic events $(\beta=-0.299, p<0.05)$. Also, traumatic events $(\beta=-0.418, p<0.01)$ were still related to physical health, indicating that the effects of traumatic events were both direct and indirect. Thus, the fifth hypothesis that perceived stress would mediate the effects of traumatic events on health was supported.

\section{Did adult abuse mediate the effects of child abuse on perceived stress and health?}

Finally, we used structural equation modelling to test our sixth hypothesis that adult abuse would mediate the effects of child abuse on perceived stress and health. The error terms of mental and physical health were allowed to correlate because mental and physical health were strongly related $(r=0.720, p<0.01)$. The path model is displayed in Figure 1. All of the path coefficients were significant and the model provided an excellent fit for the data $\left(\chi^{2}=1.445, \mathrm{df}=3, p=0.695\right.$, comparative fit index $=1.000$, Tucker-Lewis index $=$ 1.024, RMSEA (root mean square error of approximation $)=0.000$ ). This model shows that our sixth hypothesis was supported. Adult abuse mediated the effects of child abuse on perceived stress and health. In addition,

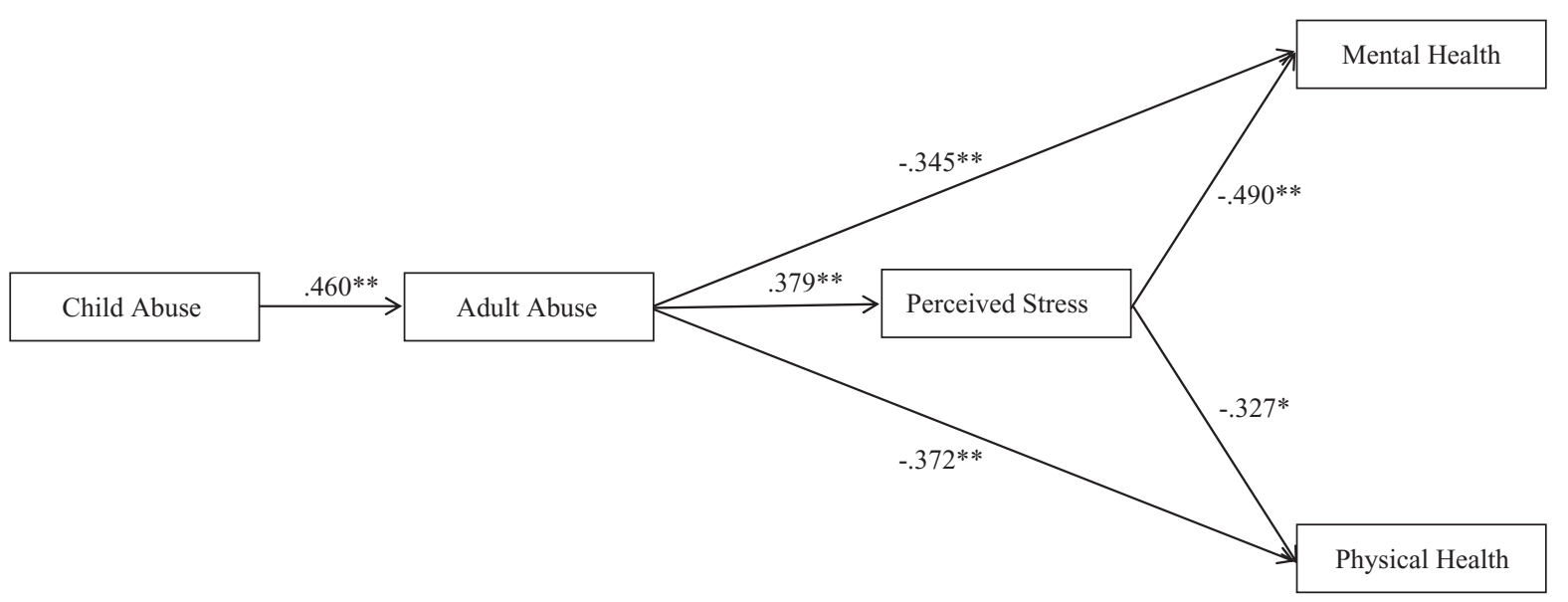

Figure 1 Path model predicting mental and physical health through perceived stress from child and adult abuse in women with fibromyalgia $\left(\chi^{2}=1.445, \mathrm{df}=3, p=0.695\right.$, comparative fit index $=1.000$, Tucker-Lewis index $=1.024$, RMSEA (root mean square error of approximation) $=0.000) ;{ }^{*} p<0.05 ;{ }^{*} p<0.01$ 
perceived stress mediated the effects of adult abuse on both mental health and physical health.

\section{Discussion}

The purpose of this study was to increase our understanding of the role of stress in FM by examining the relationship between traumatic events, perceived stress and health in women with FM and healthy women. We hypothesized and found that women with FM would report more traumatic events and perceived stress than healthy women. We also predicted that women with FM would have stronger relationships between stress and worse health. Although there was no significant difference between groups in the correlation between perceived stress and health, we found that women with FM had significantly stronger relationships between traumatic events and worse health. Finally, for the FM group, we predicted and found that perceived stress would mediate the effects of traumatic events on health and that adult abuse would mediate the effects of child abuse on perceived stress and health.

This study made several contributions to our understanding of the role of stress in the health of women with FM. Firstly, it provided new information on the idea that FM is a 'stress-related disorder' in that it involves increased exposure to stress. We identified important differences in the magnitude of group differences for various forms of stress. While women with FM had much higher levels of perceived stress $(d=$ $1.728)$, the group differences for child abuse $(d=0.867)$, adult abuse $(d=0.427)$ and other traumatic events were smaller $(d=0.105)$ and only significant for child abuse. The large difference in perceived stress provides strong support that FM is 'stress-related' with regard to the current perception and experience of stress. In addition, the larger effects sizes for child and adult abuse as compared with other traumatic events is consistent with past research regarding the importance of relationship abuse and interpersonal stress in FM (Davis et al., 2001; Walker et al., 1997; Zautra et al., 1999).

Secondly, the findings of this study provide support for the idea that FM may also be a 'stress vulnerability disorder' in that the FM group had much stronger correlations between traumatic events and current mental ( $r=-0.567$ vs. -0.165$)$ and physical health $(r=-0.539$ and -0.173 ) than for the HC group (Raphael, 2006). Thus, while FM may involve greater exposure to past traumatic events, increased reactivity to these events may also be important with regard to these women's health. In addition, our findings suggest there may be important differences in reactivity with regard to different kinds of stress. While the correlation between perceived stress and current health was comparable in both groups, the differences were greatest and significant for traumatic events. Moreover, the strongest and most consistent differences in reactivity between FM and healthy women appear to be in the domain of abusive adult relationships.

Thirdly, the results of the mediation and path analyses may provide a framework for understanding how exposure to traumatic events may affect both stress and health over time. The mediation analyses suggest that what may initially be relatively small differences in exposure to stressful events may contribute to greater ongoing perceptions that life is stressful. This is consistent with animal and human models showing that initial traumatic stressors may lead to the lasting dysregulation of stress response systems and increased sensitivity to ongoing, daily stressors (McEwen, 1998; Sapolsky, 1999). The path model provides further support for this view in that child abuse predicted adult abuse $(\beta=0.460)$, which in turn predicted both perceived stress $(\beta=0.379)$ and mental and physical health ( $\beta=-0.345$ and -0.372 , respectively). Thus, it is possible that for some child abuse may begin a cascade of events that involves long-term increases in stress and lasting negative effects on health.

These findings may have important implications for future research and interventions for people with FM. The primary implications for research may be that future studies of the role of stress in FM may benefit from considering a full range of types of stressors, the interaction of these stressors over time, and the study of the interaction of both stress exposure and stress reactivity. The difficulty in identifying the possible role of stress in the aetiology of FM may be the result of focusing on only one of these factors rather than on the complex interaction of them all. Also, if these findings are replicated with larger samples, other measures and prospective studies, then interventions may be more effective if they are tailored to focus on the type of stress or process (e.g. exposure or reactivity) is more prominent. In addition, our findings highlight the potential importance of early interventions in reducing the longterm impact of stress exposure and reactivity by breaking the cycle of relationship abuse (Bolger \& Zuckerman, 1995; Campbell et al., 2008). 
It also may be beneficial for future research to compare people with FM who have and have not experienced traumas, examine the effects of interventions in reducing the effects of trauma and examine the growth or benefits that may occur as a result of trauma (Calhoun \& Tedeschi, 2006). Comparing people with FM who have and have not experienced trauma may provide a fuller picture of the factors affecting FM and avoid psychologizing FM by overidentifying it with traumatic events (Riberto, Pato, \& Battistella, 2006). Examining the effects of trauma-focused interventions may provide more information on how traumatic events may exacerbate FM symptoms. Studying people with FM who are resilient against the pathogenic effects of trauma may provide useful clues for enhancing the coping of others with FM.

This study had several limitations. Firstly, the design was cross-sectional, making it impossible to establish causal relationships between traumatic events, perceived stress and health. Nevertheless, the results are consistent with current theories and findings about the effects of trauma and stress on health and it may be more likely that reports of past traumatic events would influence current perceptions of stress and health than vice versa (Bolger \& Zuckerman, 1995; McEwen, 1998; Sapolsky, 1999; Smith \& Zautra, 2002). Secondly, the sample was limited to women and the results may not be generalized to men with FM for whom stress may interact with their health in somewhat different ways.

Finally, the report of past traumatic events and relationships abuse are subject to retrospective and recall biases that may be influenced by current levels of stress and health. This is a central challenge to the study of the effects of traumatic events on health and needs to be addressed in long-term prospective studies (Walker \& Katon, 1996). These prospective studies are necessary for understanding differences in stress reactivity as well as exposure to stressful and traumatic events. For example, they could help determine whether an increased sensitivity to stress precedes the onset of FM symptoms and how much this may be rooted in other predisposing factors such as genetics, childhood trauma or ongoing life stress.

In conclusion, this study provided important new insights into the role of traumatic events and perceived stress in the health of women with FM. The findings showed that women with FM may have both increased exposure and increased reactivity to stress relative to healthy women. They also suggest that exposure to traumatic events may interact with increased reactivity in a way that may have a long-term and ongoing impact on perceptions of stress and health. Future research should continue to examine the complex interaction between trauma and stress in contributing to the pain, distress and disability associated with FM.

\section{REFERENCES}

Al-Allaf, A.W., Dunar, K.L., Hallum, N.S., Nosratzadeh, B., Templeton, K.D., \& Pullar, T. (2002). A case-control study examining the role of physical trauma in the onset of fibromyalgia syndrome. Rheumatology, 41, 450-453.

Baker, C.K., Norris, F.H., Jones, E.C., \& Murphy, A.D. (2009). Children trauma and adulthood physical health in Mexico. Journal of Behavioral Medicine, 32, 255-269.

Baron, R.M., \& Kenny, D.A. (1986). The moderatormediator variable distinction in social psychological research: Conceptual, strategic and statistical considerations. Journal of Personality and Social Psychology, 51, 1173-1182.

Bolger, N., \& Zuckerman, A. (1995). A framework for studying personality in the stress process. Journal Personality Social and Psychology, 69, 890-902.

Breslau, N., Kessler, R.C., Chilcoat, H.D., Schultz, L.R., Davis, G.C., \& Andreski, P. (1998). Trauma and posttraumatic stress disorder in the community: The 1996 Detroit area survey of trauma. Archives of General Psychiatry, 55, 626-632.

Calhoun, L.G., \& Tedeschi, R.G. (2006). The handbook of post-traumatic growth: Research and practice. Mahwah, NJ: Lawrence Erlbaum Associates.

Campbell, R., Greeson, M.R., Bybee, D., \& Raja, S. (2008). The co-occurrence of childhood sexual abuse, adult sexual abuse, intimate partner violence, and sexual harassment: A mediational model of posttraumatic stress disorder and physical health outcomes. Journal of Consulting and Clinical Psychology, 76, 194-207.

Cohen, S., Kamarck, T., \& Mermelstein, R. (1983). A global measure of perceived stress. Journal of Health and Social Behavior, 24, 385-396.

Davis, M.C., Zautra, A.J., \& Reich, J.W. (2001). Vulnerability to stress among women with chronic pain from fibromyalgia and osteoarthritis. Annals of Behavioral Medicine, 23, 215-226.

Desmeules, J.A., Cedraschi, C., Rapiti, E., Baumgartner, E., Finckh, A., Cohen, P., Dayer, P., \& Vischer, T.L. (2004). Neurophysiologic evidence for a central sensitization in patients with fibromyalgia. Arthritis and Rheumatism, 48, 1420-1429.

Gibb, B.E., Chelminski, I., \& Zimmerman, M. (2007). Childhood emotional, physical, and sexual abuse, and 
diagnoses of depressive and anxiety disorders in adult psychiatric outpatients. Depression and Anxiety, 24, 256-263.

Glaser, J.P., Van Os, J., Portegijs, P.J., Myin-Germeys, I. (2006). Childhood trauma and emotional reactivity to daily life stress in adult frequent attenders of general practitioners. Journal of Psychosomatic Research, 61, 229-236.

Gracely, R.H., Petzke, F., Wolf, J.M., \& Clauw, D.J. (2002). Functional magnetic resonance imaging evidence of augmented pain processing in fibromyalgia. Arthritis and Rheumatism, 46, 1333-1343.

Grant, D.M., Beck, G., Marques, L., Palyo, S.A., \& Clapp, J.D. (2008). The structure of distress following trauma: Post-traumatic stress disorder, major depressive disorder and generalized anxiety disorder. Journal of Abnormal Psychology, 117, 662-672.

Gunstead, J., Paul, R.H., Spitznagel, M.B., Cohen, R.A., Williams, L.M., Kohn, M., \& Gordon, E. (2006). Exposure to early life trauma is associated with adult obesity. Psychiatry Research, 142, 31-37.

Hyman, S.M., Paliwal, P., \& Sinha, R. (2007). Childhood maltreatment, perceived stress, and stress-related coping in recently abstinent cocaine dependent adults. Psychology of Addictive Behaviors, 21, 233-238.

Jacobsen, S., \& Bredkjaer, S.R. (1992). The prevalence of fibromyalgia and widespread chronic musculoskeletal pain in the general population (letter). Scandinavian Journal of Rheumatology, 21, 261-263.

Kleinbaum, D.G., Kupper, L.L., \& Muller, K.E. (1988). Applied regression analysis and other multivariable methods (2nd ed.). Belmont, CA: Duxbury Press.

Kubzansky, L.D., Koenen, K.C., Jones, C., \& Eaton, W.W. (2009). A prospective study of post-traumatic stress disorder symptoms and coronary heart disease in women. Health Psychology, 28, 125-130.

Maes, M., Libbrecht, I., Van Hunsel, F., Lin, A., De Clerck, L., Stevens, W., Kenis, G., de Jongh, R., Bosmans, E., \& Neels, H. (1999). The immune-inflammatory pathophysiology of fibromyalgia: Increased serum soluble gp130, the common signal transducer protein of various neurotrophic cytokines. Psychoneuroendocrinology, 24, 371-383.

McEwen, B.S. (1998). Protective and damaging effects of stress mediators: Allostasis and allostatic load. New England Journal of Medicine, 338, 171-179.

Murray, T.L., Murray, C.E., \& Daniels, M.H. (2007). Stress and family relationship functioning as indicators of the severity of fibromyalgia symptoms: A regression analysis. Stress and Health, 23, 3-8.

Nemeroff, C.B. (2004). Neurobiological consequences of childhood trauma. Journal of Clinical Psychiatry, 65(Supp 1), 18-28.
Netter, P., \& Hennig, J. (1998). The fibromyalgia syndrome as a manifestation of neuroticism? Zeitschrift für Rheumatologie, 57S, 105-108.

Norris, F.H., \& Hamblen, J.L. (2004). Standardized selfreport measures of civilian trauma and PTSD. In J.P. Wilson, T.M. Keane, \& T. Martin T (Eds), Assessing psychological trauma and PTSD (pp. 63-102). New York: Guilford Press.

Okifuji, A., \& Turk, D.C. (2002). Stress and psychophysiological dysregulation in patients with fibromyalgia syndrome. Applied Psychophysiology and Biofeedback, 27, 129-141.

Raphael, K.G. (2006). Fibromyalgia syndrome: A role for sexual abuse and other traumatic events? Primary Psychiatry, 13, 61-65.

Reynolds, A.J., Mathieson, L.C., \& Topitzes, J.W. (2009). Do early childhood interventions prevent child maltreatment?: A review of research. Child Maltreatment, 14, 182-206.

Riberto, M., Pato, T.R., \& Battistella, L.R. (2006). A comparison between post-traumatic and non-traumatic fibromyalgia. Journal of Musculoskeletal Pain, 14, 13-31.

Sapolsky, R.M. (1999). Glucocorticoids, stress and their adverse neurological effects: Relevance to aging. Experimental Gerontology, 34, 721-732.

Smith, B. W. \& Freedy, J. R. (2000). Psychosocial resource loss as a mediator of the effects of flood exposure on psychological distress and physical symptoms. Journal of Traumatic Stress, 13, 349-358.

Smith, B.W., \& Zautra, A.J. (2002). The role of personality in exposure and reactivity to interpersonal stress in relation to arthritis disease activity and negative affect in women. Health Psychology, 21, 81-88.

Smith, T.C., Wingard, D.L., Ryan, M.A., Kritz-Silverstein, D., Slymen, D.J., \& Sallis, J.F. (2009). PTSD prevalence, associated exposures and functional health outcomes in a large population-based military cohort. Public Health Reports, 124, 90-102.

Van Houdenhove, B., \& Egle, U.T. (2004). Fibromyalgia: A stress disorder? Piecing the biopsychosocial puzzle together. Psychotherapy and Psychosomatics, 73, 267-275.

Van Houdenhove, B., Neerinckx, E., Lysens, R., Vertommen, H., Van Houdenhove, L., Onghena, P., Westhovens, R., \& D'Hooghe M. (2001). Victimization in chronic fatigue syndrome and fibromyalgia in tertiary care. Psychosomatics, 42, 21-28.

Van Houdenhove, B., Neerinckx, E., Onghena, P., Vingerhoets, A., Lysens, R., \& Vertommen, H. (2002). Daily hassles reported by chronic fatigue syndrome and fibromyalgia patients in tertiary care: A controlled quantitative and qualitative study. Psychotherapy and Psychosomatics, 71, 207-213 
Vranceanu, A., Hobfoll, S.E., \& Johnson, R.J. (2007). Child multi-type maltreatment and associated depression and PTSD symptoms: The role of social support and stress. Child Abuse \& Neglect, 31, 71-84.

Walker, E.A., \& Katon, W.J. (1996). Researching the health effects of victimization: The next generation. Psychosomatic Medicine, 58, 16-17.

Walker, E.A., Keegan, D., Gardner, G., Sullivan, M., Bernstein, D., \& Katon, W.J. (1997). Psychosocial factors in fibromyalgia compared with rheumatoid arthritis: II. Sexual, physical, and emotional abuse and neglect. Psychosomatic Medicine, 59, 572-577.

Walsh, C.A., Jamieson, E., Macmillan, H., \& Boyle, M. (2007). Child abuse and chronic pain in a community survey of women. Journal of Interpersonal Violence, 22, $1536-1554$.

Ware, J.E., Snow, K.K., Kosinski, M., \& Gandek, B. (1993). SF-36 Health Survey: Manual and Interpretation Guide. Boston: The Health Institute, New England Medical Center.

Weber, D.A., \& Reynolds, C.R. (2004). Clinical perspectives on neurobiological effects of psychological trauma. Neuropsychological Review, 14, 115-129.

Weissbecker, I., Floyd, A., Dedert, E., Salmon, P., \& Sephton, S. (2006). Childhood trauma and diurnal cortisol disruption in fibromyalgia syndrome. Psychoneuroendocrinology, 31, 312-324.

Whiffen, V.E., \& Macintosh, H.B. (2005). Mediators of the link between childhood sexual abuse and emotional distress: A critical review. Trauma, Violence, \& Abuse, 6, 24-39.
Widom, C.S., Czaja, S.J., \& Dutton, M.A. (2008). Childhood victimization and lifetime revictimization. Child Abuse and Neglect, 32, 785-796.

Wolfe, F., Ross, K., Anderson, J., Russell, I.J., \& Hebert, L. (1995). The prevalence and characteristics of fibromyalgia in the general population. Arthritis and Rheumatism, 38, 19-28.

Wolfe, F.W., Smythe, H.A., Yunas, M.B., Bennett, R.M., Bombardier, C., Goldenberg, D.L. Tugwell, P., Campbell, S.M., Ables, M., Clark, P., Fam, A.G., Farber, S.J., Fiechtner, J.J., Franklin, C.M., Gattner, R.A., Hamaty, D., Lessard, J., Lichtbroun, A.S., Masi, A.T., McCain, G.A., Reynold, W.J., Romano, T.J., Russell, I.J., Sheon, R.P. (1990). The American college of rheumatology 1990 criteria for the classification of fibromyalgia. Arthritis and Rheumatism, 33, 160-172.

Young, D.R., He, X., Genkinger, J., Sapun, M., Mabry, I., \& Jehn, M. (2004). Health status among urban African American women: Associations among well-being, perceived stress, and demographic factors. Journal of Behavioral Medicine, 27, 63-76.

Zautra, A.J., Hamilton, N.A., \& Burke, H.M. (1999). Comparison of stress responses in women with two types of chronic pain: Fibromyalgia and osteoarthritis. Cognitive Therapy and Research, 23, 209-230.

Zautra, A.J., Johnson, L.M., \& Davis, M.C. (2005). Positive affect as a source of resilience for women in chronic pain. Journal of Consulting and Clinical Psychology, 73, 212-220. 